Trinity University

Digital Commons @ Trinity

Philosophy Faculty Research

Philosophy Department

$10-2008$

\title{
The Methodology of Musical Ontology: Descriptivism and Its Implications
}

Andrew Kania

Trinity University, akania@trinity.edu

Follow this and additional works at: https://digitalcommons.trinity.edu/phil_faculty

Part of the Philosophy Commons

\section{Repository Citation}

Kania, A. (2008). The methodology of musical ontology: Descriptivism and its implications. British Journal of Aesthetics, 48(4), 426-444. doi:10.1093/aesthj/ayn034

This Post-Print is brought to you for free and open access by the Philosophy Department at Digital Commons @ Trinity. It has been accepted for inclusion in Philosophy Faculty Research by an authorized administrator of Digital Commons@ Trinity. For more information, please contact jcostanz@trinity.edu. 


\title{
The Methodology of Musical Ontology: Descriptivism and its Implications
}

\author{
Andrew Kania
}

[This is a pre-copyedited, author-produced PDF of an article accepted for publication in The British Journal of Aesthetics following peer review. The version of record (Andrew Kania, “The Methodology of Musical Ontology: Descriptivism and its Implications” British Journal of Aesthetics 48 (2008): 42644) is available online at: http://bjaesthetics.oxfordjournals.org/content/48/4/426.abstract?sid=81d851444a76-4cdc-8a73-b837ce35479a. Please cite only the published version.]

\begin{abstract}
I investigate the widely held view that fundamental musical ontology should be descriptivist rather than revisionary, that is, that it should describe how we think about musical works, rather than how they are independently of our thought about them. I argue that if we take descriptivism seriously then, first, we should be sceptical of artontological arguments that appeal to independent metaphysical respectability and, second, we should give 'fictionalism' about musical works - the theory that they do not exist - more serious consideration than it is usually accorded.
\end{abstract}


...when you encounter certain things in the world, the evidence for certain things,

you realize that you have come upon somethin that you may very well not be equal to and I think that this is one of them things. When you've said that it's real and not just in your head I'm not all that sure what it is you have said. ${ }^{1}$

\section{A BRIEF HISTORY OF MUSICAL ONTOLOGY}

It is not uncommon to view debate over the ontology of music, at least in the world of analytic philosophy, as having been kick-started by the publication of Nelson Goodman's Languages of Art in $1968 .^{2}$ The ontology of music Goodman proposed is notable in at least two respects: (1) it is nominalist, identifying works with sets of concreta, specifically scores and performances, and (2) it is revisionary, in the sense that Goodman placed such a high premium on achieving what he considered to be the right kind of philosophical theory that he was explicitly prepared to revise beliefs quite central to musical practice - such as that a performance of a work might contain a wrong note - in order to preserve what he saw as the features of a good philosophical theory.

In response to Goodman, most musical ontologists have attempted to provide a less revisionary account of what a musical work is, and of the relationship between a work and a performance of it. Part of how this has been attempted, resulting in a major strand in the history of musical ontology, is through the rejection of Goodman's nominalism in favour of some other kind of metaphysical theory. This is one way to account for the diversity of ontological theories that have been defended since Goodman. Most notably, there have been two varieties of action theorists and several varieties of realists, falling into two main camps: the Platonists and 'creationists'. ${ }^{3}$ (Though there 
have also been eliminativists and idealists about musical works, these theories have been more discussed than defended since Goodman.) Most recently the wheel has come full circle, and there has been a resurgence of interest in nominalism. ${ }^{4}$ On good days, all these theories seem to me to be the 'embarrassment of riches' Amie Thomasson has characterized them as, ${ }^{5}$ though on bad days they seem like burnt-out wrecks drifting on the ontological sea.

I tend to see the early theorists in this area, most notably Goodman, Richard Wollheim, and Nicholas Wolterstorff, as approaching the ontology of art as just one more instance of the problem of universals. Musical works, they note, appear to be 'generic' entities - entities that admit of multiple instances. What kinds of things, then, could they be? The familiar answers are pretty clearly reflected in the list I have just gone through: they could be collections of concrete objects (nominalism), or abstracta that exist more or less independently (Platonism or creationism), or maybe they don't really exist at all (eliminativism), or only in our heads (idealism). Thinking about musical works in these terms gives rise to some familiar problems. For instance, if you think of a work as a kind of universal instantiated in performances, then it can seem quite a problem to explain how it is that a performance might instantiate that universal without containing all the notes that are definitive of the work.

There is a parallel history of musical ontology since Goodman, however, wherein one can discern a growing awareness that one might reject Goodman's revisionism independently of his nominalism. That is, there has been a growing interest in, or unrest about, the proper methodology for doing the ontology of music and the other arts. This strand of theorizing grew out of an interest in the nature of performance, and musical 
practice more generally. ${ }^{6}$ One of the main ideas that arose out of this work was that there must be some sort of intentional relation between a performance and the work it is of. This seems a promising route for a solution to the ‘wrong-note problem' since we might hope to find success conditions on having an intention such as to play Bach's first solo sonata for violin that are less demanding than the identity conditions of that piece. That is, you might perform a piece by seriously, or reasonably, intending to play it, and yet fail to get all the notes right. ${ }^{7}$ One reason this is an interesting development is that it doesn't appeal, at least on its face, to any particular position in what I have come to call the 'fundamentalist debate', that is, the debate about which fundamental ontological category musical works belong to, and yet it solves one of the problems that the participants in that debate are interested in.

A nice case-study for this ‘dual history’ of musical ontology is Jerrold Levinson’s seminal essay from 1980, 'What a Musical Work Is'. ${ }^{8}$ In that essay, Levinson imposes three desiderata on any ontology of (a central class of) classical musical works: such works must be (i) creatable, (ii) individuated finely, by their musico-historical contexts, and (iii) include their instrumentation essentially. Levinson goes on to deduce that musical works must belong to a new category in fundamental ontology: initiated types. ${ }^{9}$ What is an initiated type? Well, it's a generic entity that is creatable, finely individuated, and can include things like instrumentation essentially! From one point of view this can look like not very subtle sleight of hand, and there continues to be much critical discussion of the coherence of the idea of initiated types. This is the point of view that sees musical ontology as just another instance of the problem of universals. ${ }^{10}$ But from another point of view, Levinson's essay can be seen as the beginning of a concern with 
what exactly has priority when we do the ontology of art: it is implicit in the structure of Levinson's argument that the demands of the art one is attempting to understand trump the demands of metaphysics. ${ }^{11}$

In this essay I examine some recent efforts to make this methodological insight explicit, and suggest that if it is taken seriously there is one ontological theory of musical works, usually known as 'fictionalism', that deserves fuller consideration than it is usually given. Though at the end of the essay I attempt to articulate this theory clearly, and show why it should be taken more seriously, my main concern is not to defend the theory, but to uncover its connections with the methodology that many ontologists of music and the other arts appear to embrace. Similarly, I do not mount a full-scale defence

of this methodology; my concern is rather to investigate its implications. ${ }^{12}$ The belief that motivates this essay, and its moral, whether or not its arguments are convincing, is that ontologists of music and the other arts need to think more carefully about their methodology before offering various kinds of arguments in defence of their particular views. $^{13}$

\section{THE PRAGMATIC CONSTRAINT}

In his recent book, Art as Performance, David Davies defends a theory according to which works of art are not what we normally take them to be, for instance, bits of stretched canvas with paint on them, string quartets, and so on. Rather, a work of art is the extended action the artist engaged in in the production of what we pre-theoretically take to be the work. This action is so intimately tied up with the 'work-focus' or 'focus of appreciation' - the canvas, string quartet, or whatever - that we can perhaps think of that 
focus as part of the work if we accept Davies's theory, but most of our interest in works of art, as evidenced by our discourse about them, requires us to think of the work primarily in terms of the artist's 'performance' that resulted in the work. ${ }^{14}$

Davies is more explicit about his methodology than any other art ontologist. Perhaps surprisingly, given the theory he ends up defending, that methodology is one that valorises ordinary artistic practice as the data to be explained by any ontology of art, though Davies also argues that arriving at a general ontology of art will require a process of achieving 'reflective equilibrium': the philosophical equivalent of finding a smooth curve through the disparate data points that constitute our artistic practices. (Throughout I use 'artistic practice' broadly, to include critical and appreciative practice.) Davies summarizes this view in a methodological principle he calls 'the pragmatic constraint': Artworks must be entities that can bear the sorts of properties rightly ascribed to what are termed 'works' in our reflective critical and appreciative practice; that are individuated in the way such 'works' are or would be individuated, and that have the modal properties that are reasonably ascribed to 'works,' in that practice. ${ }^{15}$

On the basis of the pragmatic constraint, Davies goes on to claim that arguments in the ontology of art ought to (1) begin with what he calls an 'epistemological premise', claiming that, on reflection, our artistic practice has us attributing properties of a certain sort to what we call 'works of art', (2) continue with a methodological premise - the pragmatic constraint that works must be such as to admit of such attributions - and (3) end with an ontological conclusion that works of art must be (or cannot be) such-andsuch kinds of things (p. 23). 
How is it that with this explicit emphasis on ordinary artistic practice, Davies ends up arguing for a view that is, on the face of it, quite unintuitive? ${ }^{16}$ There is a clue in the list of kinds of attributions Davies appeals to in his statement of the pragmatic constraint (which he repeats when he comes to set out his argument schema), but it is easy to miss, since the clue lies not in what Davies includes in the list, but rather in what he leaves out. Specifically, Davies mentions (i) the actual properties we ascribe to artworks, including aesthetic and artistic properties, (ii) the modal properties we ascribe to artworks, such as that a string quartet might have had a different ending than it actually does, and (iii) the ways we individuate works of art. Notably absent is any reference to our pre-theoretical views about the ontology of artworks - the fundamental category to which they belong. Davies defends this omission by claiming that the intuitions that are strongest will be those that relate to practical aspects of [artistic] practice...rather than intuitions about what works are, ontologically speaking. I hope I speak for the reader in suggesting that, to the extent I have any intuitions about the latter, they are grounded in my intuitions about the former. (p. 22)

With this, Davies improves in two ways on the usual strategy of claiming that the intuitions defended by one's own theory are more strongly held by everyone than those one's theory refutes. First, though he speaks in such terms here, Davies does not appeal simply to intuitions, but, as mentioned above, to claims suggested by rational reflection on our artistic practice. Second, he gives a principled reason for rejecting one set of claims over another, namely that the ontological claims are grounded in the practicalones. It is this principle that I would like to call into question. 
The main objection I have to this principle is that we do have ontological intuitions about artworks that are relatively independent of our other intuitions about art ontological intuitions that are rooted in our practice. This is evident in all the prima facie counterexamples people raise when first confronted with, as we say, counterintuitive ontological proposals such as Davies’s. We think of a painting, for instance, as being spatially located, made of paint and canvas, capable of surviving beyond its artist's life and then being destroyed at some later time, and capable of being bought and sold in its entirety. We think of a musical work as coming into existence with its composition, being capable of being performed in its entirety an indefinite number of times, and being heard in its entirety at any one of these performances. ${ }^{17}$ That we have these beliefs about artworks is evident not only when we ask people about them, or when we are doing art ontology, but in just about any critical discourse, and much artistic practice. An artist typically thinks of herself as selling the whole of one of her sculptures, I take it, and sometimes wishes she had not parted with it so soon. A composer cares whether you have heard a complete performance of his piece. Critics and public alike mourn the loss of a painting in a fire.

Now, as pretty much any ontologist of art will agree, these intuitions are revisable in the light of some philosophical theorizing, in part because most people admit we can’t consistently hold on to all our intuitions. ${ }^{18}$ But the point here is that our ontological intuitions are part and parcel of our pre-theoretical beliefs about art, and must thus be taken into account along with our other intuitions. To exclude precisely our ontological intuitions from the data to be explained when we are engaged in the project of art ontology seems perverse. To draw an analogy: in working on a definition of art, a theorist 
may have recourse to some claims about the value of art, but it would be peculiar if she set aside our intuitions about the extension of the term 'art'. She might suggest revising our pre-theoretical intuitions about that extension, in the process of working out her definition, but to exclude such intuitions from the start would be to ignore the central data to be explained.

\section{AN EVEN MORE PRAGMATIC CONSTRAINT}

Guy Rohrbaugh has recently argued that we ought to do art ontology along the lines suggested by Davies, but he acknowledges that part of the data to be explained by a theory of art ontology is precisely our ontological intuitions. Thus we can see his methodology as an extension of Davies’s 'pragmatic constraint'. ${ }^{19}$ In general, Rohrbaugh argues that

[a] properly conceived ontology of art is one which provides a metaphysical framework flexible enough to represent accurately a wide variety of phenomena and to permit the expression of heterogeneous critical views, views which must be evaluated in their own terms. Ontologies of art are beholden to our artistic practices... and...critical debates are part of the practices to be captured. (pp. 178-9)

In particular, he claims we have pre-theoretical intuitions that add up to a fairly robust conception of the ontology of artworks: 'Together, these three features [of modal flexibility, temporal flexibility, and temporal existence] add up to a certain conception... about the nature of works of art' (p. 178). 
Whereas Davies must engage in damage control on the side of our ontological intuitions, Rohrbaugh sees that he will face resistance from the other direction, that is, from the direction of our 'principles' of philosophical, particularly ontological, theorizing. For while Davies's theory revolts against our ontological intuitions, the view that Rohrbaugh defends is highly intuitive, but metaphysically unorthodox. Rohrbaugh’s theory is that all artworks, but most notably multiply instantiable artworks, such as works of music and photography, are 'historical individuals', that is, 'ontologically dependent items, whose creation, continued existence, and destruction are ultimately a matter of how it goes with some other historical items' (p. 191). In other words, just as a painting is 'constituted by' its canvas and oil paint, a photograph is 'embodied in' its negative and prints. Constitution and embodiment are different relations, but Rohrbaugh argues that they are similar in a fundamental way, which he captures in the idea that both photographs and paintings are real. The sense of reality he has in mind is that these things, like ordinary objects such as tables, rocks, and trees, but unlike such abstracta as properties, have 'what you might call "a life story”. They are all subject to change over time, and...could have been somewhat different than they in fact are. Further...the existence of all such items is rooted in the physical world' (p. 199).

This widening of the scope of his conclusions is a pre-emptive strike on Rohrbaugh's part against objections that the features of artworks he describes can be accounted for by a more conservative ontology, such as a traditional nominalist or realist ontology of art. ${ }^{20}$ Rohrbaugh claims that rejecting his new category of historical individuals will have two unacceptable consequences. First, we will need to paraphrase away not just some central claims about artworks, but also central claims about species, 
words, clubs and so on, all of which Rohrbaugh suggests are historical individuals.

Second, we will lose the account of the distinction between the real and the unreal that Rohrbaugh argues we gain with his view.

One question we must ask if we are interested in the methodology of art ontology, however, is whether such a pre-emptive strike should be necessary at all. Rohrbaugh seems to be in the same position Jerrold Levinson was in once he had argued that musical works must be creatable, finely individuable, and capable of possessing instrumental properties essentially. Must one go on and provide a further metaphysical defence of the category posited, beyond the 'pragmatic' one rooted in artistic practice? Rhetorically, of course, the more defences the better. ${ }^{21}$ If one can pre-empt objections from both the artistic side and the metaphysical side, one is in a more secure position. But this muddies the methodological waters. If purely metaphysical questions are beside the point, because art-ontological disputes are to be decided on the basis of practice, then we ought to acknowledge that fact. This would simplify our task in terms of which objections we need to consider, but would be even more helpful in ruling whole methodologies out of court. $^{22}$

\section{DESCRIPTIVISM AND REVISIONISM}

One useful way of approaching these issues is through Peter Strawson's distinction between descriptive metaphysics, which 'is content to describe the actual structure of our thought about the world' and revisionary metaphysics, which 'is concerned to produce a better structure', presumably one which describes more accurately the world as it is in itself, independently of our thought about it. ${ }^{23}$ Strawson himself was concerned with the 
'most fundamental' concepts and categories, the 'commonplaces of the least refined thinking; and...yet the indispensible core of the conceptual equipment of the most sophisticated human beings' ${ }^{24}$ but if the ontology of art is constrained by ordinary artistic practice, then ontologists of art are also (or should be) engaged in a more descriptive than revisionary project. (The methodologies of Davies and Rohrbaugh, discussed above, are clearly descriptive in this sense.) Even if this is acknowledged, however, there is a question of how descriptive to be.

Although Strawson mentions that it is unlikely any metaphysician has been wholly descriptive or revisionary, ${ }^{25}$ it seems to me that we should think of theorists not as partly the one and partly the other, but as falling on a spectrum between two polar extremes. ${ }^{26}$ At the descriptive end of the spectrum is the particularist, who argues that there is no such thing as the ontological nature of the artwork, the musical work, the classical musical work for performance, or any kind of artwork. We must look at the particular details in any given case, describing each work as it is, rather than fitting them all, or any group of them, into a Procrustean ontological theory. ${ }^{27}$ For the extreme descriptivist, to describe the work as it is is simply to report how people think of it. One reason no one tends to occupy this extreme position is widespread agreement that people often think about things in a confused way. People who know nothing about a particular artwork, or the tradition in which it is produced, often form an opinion about it more quickly than those who are aware of its complexities. Since this situation gives rise to contradictory claims about any particular artwork, unless we are to revise the laws of logic, or embrace an ontological relativism about artworks, extreme descriptivism is an untenable position. Most ontologists of art, then, first restrict the judgments taken into 
account to those made by people with an understanding of the tradition in which the work was produced. Then, since even among such people there may be disagreements, most ontologists appeal explicitly or implicitly to a rational reconstruction of, or reflective equilibrium amongst the various expert judgments. Again, we have seen this above in the methodologies of both Davies and Rohrbaugh. This is already to move away from the descriptivist end of the spectrum.

As we move down the line, towards the revisionary end, we encounter ontologists who give up more and more of our expert artistic judgements in the interests of a better theory of the way artworks really are, independently of how we think about them. What counts as a better theory, apart from accounting for the data of the artistic practice in question? Of course there are the usual general theoretical ideals that are easy to list, but difficult to explain or defend: unity, simplicity, perhaps even beauty or elegance. But apart from these, many ontologists of art impose the further constraint on themselves that the kinds of entities they appeal to must be metaphysically respectable. This 'metaphysical constraint', as we might call it, is sometimes appealed to very explicitly, and made to shoulder much of the burden of defending an art-ontological theory, while in other cases it is appealed to implicitly, and considered just one constraint among many.

We have already seen a couple of examples of the latter approach in the work of Levinson and Rohrbaugh. In addition to their arguments for a new ontological category on the basis of artistic practice, each provides a defence of that category in broad metaphysical terms, appealing to entities other than artworks. Thus they implicitly endorse the idea that one’s proposed category must be not only artistically, but also metaphysically, respectable. 
A clear example of the former approach - explicitly appealing to the need for metaphysical respectability - is Julian Dodd’s recent defence of a 'simple’ type/token musical ontology, according to which musical works are more or less Platonic universals - eternal, unchanging, modally inflexible, unstructured types of sound event. ${ }^{28}$ One of the mainstays of Dodd's defence of this position is the claim that, in contrast to other metaphysical entities, types, and the relation that tokens bear to them, are well understood, holding an unimpeachable place in any general ontology. For instance, at the beginning of his book, Dodd claims that immediately upon noting that musical works are repeatable, we are invited to treat musical works as types because... we thereby provide a familiar and plausible explanation of the nature of the relation holding between a work and its occurrences. ... Rather than being a queer relation of embodiment, it turns out to be just one more example of the familiar relation that holds, for instance, between the word 'table' and its token inscriptions and utterances. ${ }^{29}$

Dodd goes on throughout the book to defend his theory in large part on the basis of the metaphysical respectability of types: first, as opposed to the metaphysical obscurity of the entities posited by rival theories and, second, despite the plethora of unintuitive consequences that follow from his own theory.

Though this kind of strategy is familiar, and apparently accepted by most people engaged in these debates, it should give us serious pause. For if a 'pragmatic', descriptivist approach to the ontology of art is the correct one, then it is not clear what force such appeals to general metaphysical claims or theories should have. If in proposing a theory of the ontology of art we are really offering a description of the 'structure of our 
thought' about artworks, then the existence and nature of such philosophical arcana as types, properties, and so on, look like they might be beside the point, just as the laws of physics that govern the structural integrity of tables and chairs are irrelevant to whether something counts as a table or a chair.

A defender of the metaphysical constraint might respond as follows. He could point out that the kinds of 'metaphysical' debate I am suggesting we might do without are in fact correctly described as descriptivist. The point of descriptivism, it might be said, is to change not the way we go about metaphysics, but how we conceive of what we are doing. Instead of having the rather surprising goal of figuring out from our armchairs how the world is independently of our thought about it, we should acknowledge that we are trying to figure out how we ultimately conceive of the world. So it is a mistake to draw an analogy between musical works and fundamental ontology, on the one hand, and furniture and physics on the other. Physics is revisionary - it cares about how things really are, not about how we think about them - but fundamental metaphysics may well be as descriptive as musical ontology. Thus our ontological theories of music should cohere with our fundamental ontological theories - we can radically revise our intuitions about the ontological nature of musical works while being thoroughgoing descriptivists.

While I am sympathetic to the premises of this argument, I reject the conclusion. The fact, if it is one, that fundamental metaphysics is descriptive does not directly imply that our 'higher-order' ontologies must mesh with our fundamental ontology. ${ }^{30}$ In part this is because (pace David Davies) those involved in the arts think about the nature of artworks quite a lot, and often quite explicitly. By contrast, few people other than metaphysicians think about the nature of objects and their properties, say. Thus, there is 
no reason to expect that the way we think about musical works will mesh with, for instance, the way we think about electrons having particular spins. Furthermore, though musical works must have some fundamental nature, if they exist at all, it does not follow that they will be metaphysically fundamental in the same sense as substances or tropes might be. Musical works get made in complex social situations - they are cultural artefacts. Part of what this means is that their nature and properties depend not only on individual minds but on complex interactions between many different minds, and thus they will be at least as high up the ontological ladder as minds. ${ }^{31}$ It is surely something like this thought that is behind the idea that musical ontology is ineliminably descriptive, because if this is correct, then how musical works are depends upon how people think about them.

An alternative response would be to defend revisionism about general metaphysics. Consideration of such a defence is beyond the scope of this essay, fortunately for me. But I hope it is clear that the replies given to the previous response are equally applicable here. The fact, if it is one, that fundamental metaphysics is revisionary does not directly imply that musical ontology is revisionary. Moreover, the considerations given above about the dependence of musical works on complex social practices give us reason to suspect that musical ontology is descriptive whether or not fundamental metaphysics is.

Finally, one might explicitly defend revisionism about musical ontology. Considering such a defence is also beyond the scope of this essay. I will just point out here that a return to revisionism would be a return to the bad old Goodman days - the days when artistic practice played no more role in our art-ontological theories than 
delimiting a set of phenomena to be investigated. If the ontology of art has changed for the better since those days, in becoming more answerable to artistic practice, then whatever reasons we have for approving of those changes will be reasons to reject artontological revisionism.

In sum, if art ontology is a truly descriptivist field, then ontological theories of other domains, such as fundamental metaphysics, are beside the point. As mentioned above, we may be justified in thinking that our ontological theories of art (as with our theories of everything else) must obey the laws of logic, but if they are truly descriptive they are not beholden to anything else, apart from our artistic practice, in ways already discussed. If the best rational reconstruction of the ontological conception of artworks implicit in artistic practice is that they are $\mathrm{X}, \mathrm{Y}$, and $\mathrm{Z}$, then artworks are in fact the kind of thing that is $\mathrm{X}, \mathrm{Y}$, and $\mathrm{Z}$.

\section{DESCRIPTIVISM AND FICTIONALISM}

It would be nice to be able to explain how it is that our musical practices determine the fundamental ontological nature of musical works. With such a theory in hand, we could truly embrace descriptivism about musical ontology and eschew the more technical, apparently revisionist discussions of musical ontology so prevalent in the literature.

One might think that Amie Thomasson's recent work on the reference of art-kind terms provides a way of integrating a descriptivist approach to art ontology with a concern for fundamental metaphysics. ${ }^{32}$ In short, Thomasson argues that if we refer with art-kind terms at all, it is to things with the basic ontological properties that we conceive those kinds as possessing. A problem arises if there are no such things, though. In that 
case, Thomasson claims that we refer to the closest ontological competitor. However, if we fail to refer to what we thought we referred to with some art-kind term, it is not clear that we must be referring instead to the closest competitor to the ontological conception implicit in our practice; we might simply fail to refer. Furthermore, if we do refer to some closest competitor, it seems likely that in our attempts to find that competitor we will be led away from descriptivism to the kind of revisionism we would like to avoid. ${ }^{33}$

Another place it is tempting to look for such an explanation is the literature on 'social construction'. For there we find discussions of how it is that by merely acting in certain ways, we bring it about that certain things are (correctly) classified in certain ways. Unfortunately, for our purposes, most of this work is concerned not with the construction of things, but with the construction of concepts or categories of things, or, at best, the attribution of new properties to pre-existing things. ${ }^{34}$ Since the major issue in fundamental musical ontology is the nature of the things themselves - musical works this avenue is not as promising as it might at first appear.

There is another approach which I believe merits more serious consideration than it is usually afforded. This view is usually labelled 'fictionalism', but in the interests of approaching it with fresh eyes, I will introduce it through a similar theory about language recently defended by Georges Rey. Rey’s central claim is that 'standard linguistic entities' (SLEs), such as phonemes, words, and sentences, are 'intentional inexistents'. ${ }^{35}$ What he means by this is that (a) there are no such things, either outside the mind in the concrete or abstract realms, or inside the mind, but that (b) there is a quite robust shared system of representations of such things. Part of the motivation for the view is that the most successful linguistic theories refer to such things as sentences with complex 
grammatical structure, yet at the same time linguistics provides evidence that there are no token sentences with such structure. ${ }^{36}$ The ultimate explanation of how we communicate by means of sentences when there don't seem to be any, strictly speaking, is that we are engaged in

a kind of folie à deux (or à $n$, for the $n$ speakers of a common language): the speaker has the illusion of producing an SLE that the hearer has the illusion of hearing, with however the happy result that the hearer is usually able to determine precisely what the speaker intended to utter. ... [The] existence [of SLEs] is completely inessential to the success of normal communication and to the needs of linguistic theory. ${ }^{37}$

It is worth considering whether musical works may be such 'intentional inexistents'. We discover the kinds of properties musical works must have (creatability, and so on) by investigating musical practice, just as we discover what properties sentences must have by investigating linguistic practice. While the claim that there are no musical works with these properties is not as well-established as the parallel linguistic claim, the ongoing and seemingly intractable disputes about the fundamental metaphysical nature of musical works seems akin to the linguists' evidence that there are no sentences with the requisite structure. ${ }^{38}$ More loosely, the ways musical ideas are disseminated through works is analogous to the way ideas are disseminated through language: They are set down in writing, and communicated through 'utterances' (performances), none of which need match the structure of the work perfectly. Certainly there is a robust system of representing works in our compositional, performative, and 
critical musical practices. In short, it would make no difference if there were no musical works, strictly speaking, as long as we all continued to behave as if there were.

It might seem puzzling at first that pursuing descriptivism could result in such an unintuitive theory. We seem to be in a similar dialectical position to that of David Davies, according to the account I gave above. But this is not so. If we truly embrace descriptivism, we embrace the idea that when we do musical ontology, what we describe is our conceptions of musical works, rather than the things themselves. There is a certain irony in the idea that if we take descriptivism, and thus our conceptions of musical works, seriously, we should conclude that those works have no existence beyond our conceptions of them. But this irony should be softened by the security our conceptions of musical works gain against revisionist attacks.

Given the descriptivist retreat to explication of our concepts of musical works, should we be agnostic or quietist about their existence, rather asserting their inexistence? To answer this question in full would require at least another essay, but there is one basic reason, analogous to that Rey has for asserting the inexistence of SLEs, to prefer 'atheism' about musical works to agnosticism. In essence it is an appeal to Occam's razor. If we are not required to posit the existence of musical works as we conceive them in order to account for the data our ontological theory must explain, then we should not. ${ }^{39}$ Having briefly set out this variety of fictionalism about musical works, let me distinguish it from some views with which it might be confused. First, this view should be clearly distinguished from eliminativism. Eliminativists about Xs argue that we ought to stop talking about Xs, and start talking about Ys, which were really what we were talking about all along, albeit confusedly. ${ }^{40}$ Rey does not suggest this for linguistic 
entities, nor does the fictionalist for musical works. Part of the reason for this is that, on the view proposed, while there aren’t really any Xs, there aren't any Ys, either. If there aren’t any musical works, we are getting along fine without them, and there is no reason to change this happy state of affairs.

Second, fictionalism should be distinguished from nominalism, both narrowly and broadly construed. In the narrow sense, nominalist proposals about musical ontology are close to eliminativist, or at least reductionist, proposals. The nominalist seeks to identify works with things, such as scores and performances, or sets thereof, that are more familiar to us than what is posited by other theories, such as types or historical individuals. Again, we are getting along fine talking about musical works in addition to performances, scores, and so on, not to mention the problems that arise when we try to reduce work-talk to performance-talk, and so on. In the broad sense, nominalists are those who attempt to do away with all abstract objects. This is not the place to go into that dispute, but I should at least note that the arguments for the intentional inexistence of linguistic entities and musical works do not warrant such a broad conclusion. It is not at all clear that the arguments for the inexistence of phonemes or musical works could be extended to numbers or properties. ${ }^{41}$

Third, the view should be distinguished from idealism. The claim is not that musical works are mental entities, any more than the claim that there are no witches is the claim that witches are our thoughts about witches. What is 'ideal' (i.e., mental or psychological) according to the proposal is only our thoughts about musical works. But this doesn’t distinguish musical works from anything else. The distinctive claim is that there are no musical works, ideal or otherwise, but that we have thoughts 'about them' 
nonetheless. This kind of talk always has an air of paradox about it, but there is nothing more problematic here than our usual 'references to' the Greek gods, witches, and so on. ${ }^{42}$ Of course, one might object that such reference is problematic enough. All I can do here is suggest that if we can talk about witches without there being such things - real, abstract, ideal, or otherwise - we can do the same for musical works. We ought not to talk seriously about witches because of the pernicious social results of such talk. But though similar arguments about musical works may be possible, our ongoing musical practices are presumably rather valuable, and thus there is no need to change those practices to bring them into accord with the inexistence of musical works (whatever that would entail!).

Need or no, you might wonder if musical practice could remain unchanged, at least for those who have embraced the theory. For surely if you don't believe there are any musical works, you can’t seriously intend to play one, for instance. The fictionalist can first respond that it will be very difficult even for himself to take this theory seriously in practice, so thoroughly enmeshed are we in our conceptual scheme about music. (Think of the analogous difficulty of expressing explicitly the fictional status of characters and events in a film under discussion.) But, second, even if one could keep the theory at the forefront of one's mind, all one would have to do would be to explicitly intend to produce a sound event (or whatever) that would be taken by a knowledgeable listener to be a performance of a particular work. Similarly for the philosopher of language who can’t stop thinking about the intentional inexistence of SLEs. She can still communicate with other people, even though she knows that she is not really producing token sentences with the structure her linguistic theory 'requires' of them. 
Finally, if fictionalism is embraced, what are the consequences for the study of musical ontology? To ask this is perhaps to come full circle. We arrived at fictionalism by taking the path of descriptivism seriously. Thus it is not surprising if fictionalism leads us to be descriptivists. Rather than putting the point in this circular fashion, though, it is more accurate to see descriptivism and fictionalism as going hand in hand. If we are descriptivists, it seems to me that much musical ontology can go on as before. Consider higher-level musical ontology. The question, for example, of whether works of rock music are songs for a kind of performance or replete recordings for playback is independent of the fundamental metaphysical nature of repeatable sonic entities (be they songs or recordings). This question has largely, and rightly, been addressed by examining our musical practice - that is, descriptively. It is no more reasonable to object to this debate on fictionalist grounds that there are no musical works than it is to object to a debate about Hamlet's motivations on the grounds that there is no such person.

Fundamental musical ontology is a little more problematic, since there is a little more cognitive dissonance in making claims about the fundamental nature of musical works while maintaining there are no such things. But, again, as long as we keep the tenets of descriptivism and fictionalism clearly in mind, there is in fact no incoherence here. To say that musical works are repeatable, and thus types or sound structures, is shorthand for saying that we conceive of musical works as repeatable, and thus as types or sound structures. There is still plenty of room for debate over exactly how we conceive of musical works. Is instrumentation essential to them? Are they timeless entities or tethered to their contexts of creation? And so on. All of these questions can be asked about how we conceive of musical works while maintaining that, strictly speaking, there are no such 
things. One methodological advance we can make as descriptivist fictionalists is to rule out certain manoeuvres, such as objecting to an ontological proposal on the grounds that, although it is an accurate reflection of the conception of musical works implicit in our practice, it is metaphysically indefensible.

\section{CONCLUSIONS}

Many musical (and other art) ontologists seem to embrace what I have called a descriptivist methodology. I have argued that if we take descriptivism seriously, we should also take seriously the theory that there may be no such things as musical works, independent of our conceptions of them. Though this theory is counterintuitive, it has the advantage of allowing us to embrace descriptivism wholeheartedly, and to reject certain kinds of arguments about musical ontology, such as those appealing to the 'metaphysical constraint' that such theories must be independently metaphysical defensible. Even if these conclusions are thought incorrect, I hope to have shown that art ontologists would do well to examine their methods more closely. ${ }^{43}$

Andrew Kania, Department of Philosophy, Trinity University, San Antonio, TX 78212, USA. Email: akania@trinity.edu 


\section{Notes}

${ }^{1}$ Cormac McCarthy, No Country for Old Men (New York: Vintage, 2005), p. 299.

${ }^{2}$ Nelson Goodman, Languages of Art (Indianapolis, IN: Bobbs-Merrill, 1968).

3 The main action theorists are Gregory Currie and David Davies; Peter Kivy and Jerrold Levinson are exemplary proponents of Platonism and creationism, respectively. (Gregory Currie, An Ontology of Art [New York, NY: St. Martin’s Press, 1989]; David Davies, Art as Performance [Malden, MA: Blackwell, 2004]; Peter Kivy, The Fine Art of Repetition [Cambridge, Cambridge U.P., 1993], pp. 35-74; Jerrold Levinson, 'What a Musical Work Is’, reprinted in his Music, Art, \& Metaphysics [Ithaca, NY: Cornell University Press, 1990], pp. 63-88.)

${ }^{4}$ I have in mind recent work by Stefano Predelli, and Ben Caplan and Carl Matheson, for example: Stefano Predelli, 'Goodman and the Score’, British Journal of Aesthetics, vol. 39 (1999), pp. 138-47, and 'Goodman and the Wrong Note Paradox’, British Journal of Aesthetics, vol. 39 (1999), pp. 364-75; Ben Caplan and Carl Matheson, 'Defending Musical Perdurantism’, British Journal of Aesthetics, vol. 46 (2006), pp. 59-69. 5 'The Ontology of Art and Knowledge in Aesthetics', Journal of Aesthetics and Art Criticism, vol. 62 (2005), p. 221.

${ }^{6}$ See, in particular, Jerrold Levinson's Music, Art, \& Metaphysics; Stephen Davies, Themes in the Philosophy of Music (Oxford: Oxford U.P., 2003); and Stan Godlovitch, Musical Performance: A Philosophical Study (London: Routledge, 1998). This interest in performance is present even in the work of some of the early figures I have mentioned, most notably Wolterstorff, but is more evident in work that came after them.

${ }^{7}$ This point is nicely encapsulated by Stefano Predelli in 'Against Musical Platonism', British Journal of Aesthetics, vol. 35 (1995), pp. 347-9. A helpful recent overview of the 
nature of intentions and their relation to art is Paisley Livingston's Art and Intention: A Philosophical Study (Oxford: Oxford U.P., 2005).

${ }^{8}$ Reprinted in his Music, Art, \& Metaphysics, pp. 63-88.

${ }^{9}$ More specifically, Levinson claims that musical works are 'indicated structures' - one major class of initiated type - but I pass over these details here.

${ }^{10}$ See, for example, Robert Howell, 'Types, Indicated and Initiated', British Journal of Aesthetics, vol. 42 (2002), pp. 105-27; Saam Trivedi, 'Against Musical Works as Eternal Types’, British Journal of Aesthetics, vol. 42 (2002), pp. 73-82; Ben Caplan and Carl Matheson, ‘Can a Musical Work be Created?’, British Journal of Aesthetics, vol. 44 (2004), pp. 113-34, and ‘Defending Musical Perdurantism’; and Julian Dodd, Works of Music: An Essay in Ontology (Oxford: Oxford University Press, 2007), particularly pp. 58-142.

${ }^{11}$ For some recent examples of work from this second point of view, see Guy Rohrbaugh, ‘Artworks as Historical Individuals’, European Journal of Philosophy, vol. 11 (2003), pp. 177-205; David Davies, Art as Performance; and Amie Thomasson, 'The Ontology of Art and Knowledge in Aesthetics', Journal of Aesthetics and Art Criticism, vol. 63 (2005), pp. 221-9, and 'Debates about the Ontology of Art: What Are We Doing Here?', Philosophy Compass, vol. 1 (2006), pp. 245-55.

As with the early history of analytic musical ontology, the division between these points of view is not as clear-cut as I suggest here. Many of those listed in the previous note are sensitive to contextualist issues, and those listed in this note engage in what might appropriately be labelled 'technical' metaphysical disputes. Nonetheless, I think 
the division is a helpful heuristic in approaching even the arguments of those with a foot in each camp.

${ }^{12}$ Perhaps the best recent defense of this methodology is that of David Davies in Art as Performance, pp. 16-24, where he also gives references to important predecessors.

${ }^{13}$ As this last sentence suggests, if what I have to say about music here is cogent, it will doubtless have application to other arts with ontologically multiple works, such as photography, and may extend to ontologically singular artforms, such as painting. Nonetheless, I focus my discussion by primarily considering musical ontology. ${ }^{14}$ I will not discuss Davies’s ontological theory in detail, since here I am primarily interested in the proper methodology for art ontology rather than in particular ontological theories. For a brief discussion of Davies's theory, see my review of Art as Performance in Mind, vol. 114 (2005), pp. 137-41.

${ }^{15}$ Art as Performance, p. 18. All parenthetical references in this section are to this book. 16 There will be a fair amount of reference to intuitions in what follows. There has been some debate recently about both how intuitions should be measured, and whether they should be accorded the philosophical weight they traditionally have been. Such considerations are beyond the scope of this essay, in part because of its semi-historical nature, and in part because this is a topic for another time. For a start, see Roy Sorenson, Thought Experiments (Oxford: Oxford University Press, 1992), Timothy Williamson, The Philosophy of Philosophy (Oxford, Blackwell, 2007), chapters 5-8, and Joshua Knobe, ‘Experimental Philosophy’, Philosophy Compass, vol. 2 (2007), pp. 81-92.

${ }^{17}$ Not all of these claims are inconsistent with Davies's performance theory; my point is just that we have intuitions about the ontology of artworks. 
${ }^{18}$ Davies himself puts this point very clearly. He submits that our pre-theoretical intuitions (or at least a subset thereof) add up to an empiricist theory of art, consisting, at least, of ontological, epistemological, axiological, and definitional theses, but argues, compellingly, that such a theory cannot account for many of our central artistic practices, and must thus be revised (Art as Performance, pp. 6-7). Note that this empiricist theory contains an ontological thesis, and that Davies claims it 'is deeply ingrained in our ordinary ways of thinking about art, and seems to be entailed by central features of our appreciative and critical practice’ (p. 6). This seems to imply that we do, in fact, have pre-theoretical ontological intuitions about works of art. I suspect that Davies would attempt to draw a sharp line between artistic practice and our ordinary ways of thinking about art or what seems to be entailed by our artistic practice, claiming that the latter are theoretical, not practical, and thus secondary to practice. I am not convinced there is such a sharp line.

${ }^{19}$ Guy Rohrbaugh, ‘Artworks as Historical Individuals’. (All parenthetical references in this section are to this article.) This is a 'rational reconstruction' of the dialectic, since Rohrbaugh's view predates Davies’s, at least in print.

${ }^{20}$ Julian Dodd mounts an attack of this sort on Rohrbaugh's view in Works of Music, pp. 143-66.

${ }^{21}$ Note that in 'What a Musical Work Is', and elsewhere, Levinson makes the same move as Rohrbaugh, appealing to a range of non-art entities that he claims are indicated types. ${ }^{22}$ I have in mind here the more technical discussions of the nature of types, indicated and otherwise, the cost-benefit analyses of nominalism vs. realism about musical works, and 
so on. These discussions are found in the work of those who take the first, more revisionary point of view, discussed in the first section and below.

${ }^{23}$ Peter Strawson, Individuals: An Essay in Descriptive Metaphysics (Garden City, NY: Anchor, 1963), p. xiii. Though Strawson says little about the ontology of art in Individuals, he explicitly argues that his fundamental metaphysical project does not differ in kind from more specialized philosophical projects, such as art ontology, but 'only in scope and generality’ (p. xiii). He briefly discusses the ontology of art on page 239. ${ }^{24}$ Individuals, p. xiv. I should emphasize that I am not endorsing Strawson’s descriptivism about metaphysics in general; I am just making use of his helpful distinction.

${ }^{25}$ Individuals, p. xiii.

${ }^{26}$ At this point, then, I leave Strawson’s particular descriptivism behind. A good summary of his views about the methodology of metaphysics can be found in his Analysis and Metaphysics: An Introduction to Philosophy (Oxford: Oxford U.P., 1991). ${ }^{27}$ Lee Brown is the only philosopher I am aware of who defends this kind of view explicitly ('The Ontology of Popular Music: A Philosophical Snipe Hunt?’, unpublished manuscript), but one could see, for instance, Stephen Davies’s arguments for a diverse ontology of music as a push towards the particularist end of the spectrum ('Ontologies of Musical Works', in Davies’s Themes in the Philosophy of Music, pp. 30-46.)

${ }^{28}$ Works of Music, passim. In fact, Dodd argues that musical works are norm-types, but I follow his lead in leaving out the complications introduced by this fact when first setting out the theory.

${ }^{29}$ Works of Music, p. 11. 
${ }^{30}$ Here I refer to fundamental musical ontology as 'higher-order' compared to fundamental general metaphysics. This should not be confused with the distinction between fundamental musical ontology and higher-order musical ontology. On the latter distinction, see my 'New Waves in Musical Ontology', in Kathleen Stock and Katherine Thomson-Jones (eds) New Waves in Aesthetics, (New York: Palgrave Macmillan, forthcoming).

${ }^{31}$ For discussion of these issues, see the essays in part one of Eric Margolis and Stephen Laurence (eds), Creations of the Mind: Theories of Artifacts and their Representation (Oxford: Oxford U.P., 2007).

${ }^{32}$ Amie Thomasson, 'The Ontology of Art and Knowledge in Aesthetics', Journal of Aesthetics and Art Criticism, vol. 63 (2005), pp. 221-9, and 'Debates about the Ontology of Art: What Are We Doing Here?', Philosophy Compass, vol. 1 (2006), pp. 245-55.

33 I discuss Thomasson's work in more depth in 'New Waves in Musical Ontology'. 34 Two good recent overviews of social construction are Sally Haslanger, 'Feminist Metaphysics', in Edward N. Zalta (ed.) The Stanford Encyclopedia of Philosophy (Spring 2007 Edition), URL = <http://plato.stanford.edu/archives/spr2007/entries/feminismmetaphysics/>, and Ron Mallon, ‘A Field Guide to Social Construction’, Philosophy Compass, vol. 2 (2007), pp. 93-108.

${ }^{35}$ Georges Rey, 'The Intentional Inexistence of Language - But Not Cars', in Robert Stainton (ed.) Contemporary Debates in Cognitive Science, (Oxford: Blackwell, 2006), pp. 237-55; 'Mind, Intentionality and Inexistence: An Overview of My Work', Croatian Journal of Philosophy, vol. 5 (2005), pp. 389-415 (followed by several commentaries, and Rey’s replies). 
${ }^{36}$ Physical items like the thing you are casting your eyes over right now (or the sounds you would produce if you read this out loud) do not count as sentence tokens because a sentence, according to our best linguistic theories, is not just a sequence of letters or sounds, but something with a very complex 'tree structure'. Rey argues that there are not even token physical items or events with such structure in our minds or brains. ('The Intentional Inexistence of Language’, pp. 244-7, 249-50, and 253, n. 8; 'Intentional Content and a Chomskian Linguistics’, in Alex Barber (ed.) Epistemology of Language, (Oxford: Oxford U.P., 2003), pp. 166-83.)

${ }^{37}$ Rey, 'The Intentional Inexistence of Language’, pp. 240-1.

${ }^{38}$ While such disputes are found throughout metaphysics, and thus by parity could be seen as reason for adopting fictionalism about all sort of things, the cost of adopting fictionalism about musical works is much smaller than that of adopting fictionalism about persons, ordinary objects, and so on, as I indicate briefly below.

${ }^{39}$ A rather grandiose analogy may be drawn to Kant's transcendental idealism. Even if a Kantian acknowledges the possibility of 'Trendelenburg's alternative', that things as they are in themselves really are spatio-temporal, just as we conceive them to be, she has no reason to think that this possibility obtains. For a concise overview of this topic, see Sebastian Gardner's Routledge Philosophy Guidebook to Kant and the Critique of Pure Reason, (London: Routledge, 1999), pp. 107-11.

${ }^{40}$ For an eliminativist proposal about musical works, see Richard Rudner, 'The Ontological Status of the Esthetic Object', Philosophy and Phenomenological Research, vol. 10 (1950), pp. 380-8. Eliminativist proposals are better known in the philosophy of mind. For an introduction to such theories, see William Ramsey, 'Eliminative 
Materialism', in Edward N. Zalta (ed.) The Stanford Encyclopedia of Philosophy (Winter 2007 Edition), URL = <http://plato.stanford.edu/archives/win2007/entries/materialismeliminative/>.

${ }^{41}$ For a little more on this last point, see Rey, 'The Intentional Inexistence of Language’, p. 250.

${ }^{42}$ It is not by accident that I omit fictional characters from this brief list of examples. What distinguishes gods and witches from fictional characters is that, at least while such discourse was taken seriously, people believed that there really were such things. By contrast, I am in accord with those who argue that our engagement with works of fiction is a matter of imagination or make-believe. This is a reason for unease about the label of 'fictionalism', since I do not want to suggest that we standardly imagine that there are such things as musical works. However, the label seems well enough established that I will not try to unseat it here.

${ }^{43}$ This essay would not have been written without the support of Julie Post and the Writers' Bloc, all of whom I thank. Thanks also to Stephen Davies, Jerrold Levinson, and two readers for the journal for many incisive comments, and to the British Society for Aesthetics for the honour of awarding this essay their prize.

I dedicate this essay to Peter Lamarque for his fine editorship of the British Journal of Aesthetics over the past thirteen years. 